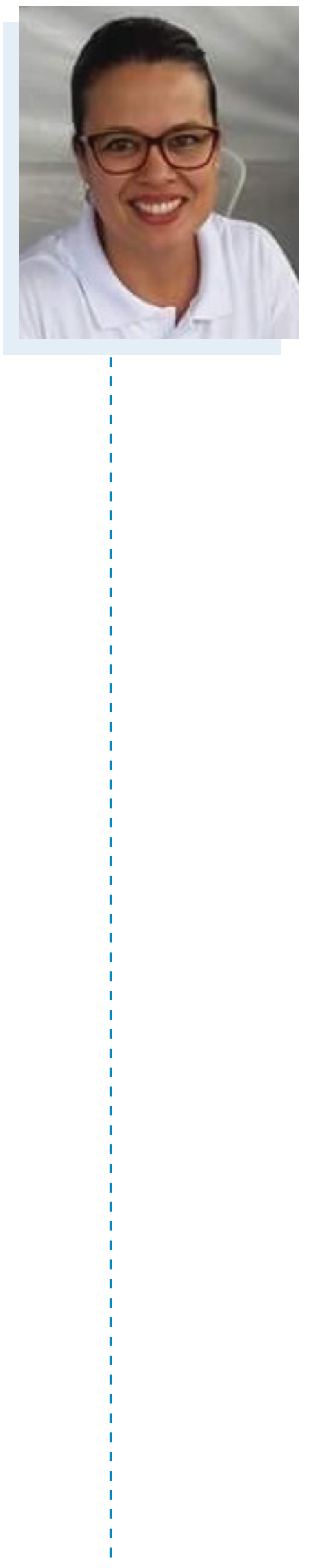

\title{
Atuação do enfermeiro na área de incontinências: podemos fazer mais
}

Nurses' performance in the area of incontinence: we can do more Actuación del enfermero en el área de incontinencias: podemos hacer más

\author{
Gisela Maria Assis
}

ORCID ID

Assis GM DiD https://orcid.org/0000-0001-6343-8075

\section{COMO CITAR}

Assis GM. Atuação do enfermeiro na área de incontinências: podemos fazer mais. ESTIMA, Braz. J. Enterostomal Ther., 17: e0719. https:// doi.org/10.30886/estima.v17.761_PT

Quero convidá-lo à uma reflexão sobre a atuação da nossa estimada estomaterapia na área de incontinências. Ou, como prefiro me referir a ela, a área das disfunções miccionais e evacuatórias, compreendendo que as disfunções vão além da perda urinária ou fecal, contemplando também a retenção urinária e a constipação intestinal.

Pense, por um instante, a que grupos você pertence hoje, colegas de estudo, de trabalho, família, amigos de infância... quantas pessoas compõem suas redes sociais? Experimente perguntar, em qualquer desses grupos, se alguém acha que vai ao banheiro mais vezes do que outras pessoas, se já perdeu algumas gotas de urina dando risada ou chegando ao banheiro, se tem dificuldade com a evacuação ou se o filho urina na cama mesmo tendo mais de cinco anos. Pergunte, também, que impacto isso já causou em sua vida. Você se surpreenderá com as respostas. Em todos os grupos existe alguém que vive com esses problemas ou que conhece quem os viva. A International Continence Society divulgou, com base em revisões, que se considerarmos qualquer tipo de incontinência urinária, a prevalência é de 25 a 45\%, ou seja, no mínimo duas em cada 10 pessoas convivem com a perda involuntária de urina ${ }^{1}$.

Atuando nessa área há mais de 13 anos, diante da demanda expressiva do serviço de saúde público brasileiro, ouso dizer, por experiência, que essas pessoas não têm tido a assistência que precisam e que merecem. Inicialmente, essas pessoas nem procuram o serviço de saúde, por desconhecimento do que os sintomas representam ou por vergonha de tratar do assunto com um profissional. Quando chegam a procurar por ajuda profissional, deparam-se, frequentemente, com profissionais que também não têm conhecimento para lhes ajudar ou que partem para abordagens cirúrgicas ou medicamentosas, com seus riscos e consequências, sem que essa 
seja a abordagem recomendada como primeira linha de tratamento, sendo que há tanto a se fazer de forma conservadora, com tão bons resultados².

Quando, por um lado, deparo-me com a realidade do sistema de saúde, por outro percebo o quanto nós, enfermeiros, podemos fazer por essas pessoas. Podemos atuar na prevenção por meio da divulgação de medidas simples que evitariam a manifestação da incontinência ou de suas complicações, agir precocemente nos sintomas por meio de orientação de medidas comportamentais simples (controle de intervalo miccional, posicionamento para eliminações, ingestão de água, treinamento muscular de assoalho pélvico), contribuir para o resgate da autonomia e da qualidade de vida à mulher com prolapsos de órgão pélvicos pela inserção de pessários vaginais ou à pessoa com disfunção neurológica de trato urinário inferior pela capacitação para o cateterismo intermitente limpo ${ }^{3}$.

As ações especializadas do enfermeiro previnem e tratam as disfunções miccionais e evacuatórias de forma efetiva. O Conselho Federal de Enfermagem, em seu Parecer 04/2016/CTAS/COFEN, nos respalda para tal prática. Entendo o enfermeiro como a força motriz da equipe de saúde, capaz de mudar a realidade das incontinências no sistema de saúde brasileiro, sem desconsiderar, de forma alguma, a importância da ação dos outros profissionais envolvidos nessa área de atuação.

Apesar de não sermos em muitos especialistas no país, acredito ser importante assumirmos nossa responsabilidade social, tanto no sentido de prestar assistência especializada quanto de capacitar enfermeiros generalistas a atuar nas tantas ações que não são exclusivas do enfermeiro estomaterapeuta.

Nós, enfermeiros, estamos em todos os lugares e em todos os níveis de atenção à saúde; se trabalharmos na educação em saúde, estaremos contribuindo para evitar muitos casos de incontinências. Se o tratamento precoce compuser a ação do enfermeiro na atenção básica, reduziremos as filas para hospitais especializados e garantiremos a atenção secundária a casos mais complexos, otimizando o direcionamento de recursos.

Indo além, precisamos compartilhar nossas ações, nossos sucessos e insucessos na área. A pesquisa nos permite essa troca, esse aprender com os erros e acertos do outro, esse evoluir em grupo e como categoria.

Nessa linha de "podemos fazer mais" diante desse cenário nacional, criei, com mais duas enfermeiras estomaterapeutas, a iniciativa chamada Fluir, com a ideia de unirmos forças para mudar essa realidade. Realizamos ações de conscientização da população a respeito da prevenção e tratamento da incontinência urinária, por meio de palestras, rodas de conversa, páginas em redes sociais e mídias em geral. Temos a intenção de contribuir com a formação de enfermeiros para atuar na atenção à pessoa com disfunções miccionais e evacuatórias, desde a atenção básica até a ação especializada. Pretendemos manter uma linha constante de pesquisa, a fim de consolidar a literatura de enfermagem na área.

A iniciativa que criamos é para a população, para a estomaterapia, para a enfermagem, para o sistema de saúde; é para você que acredita que pode transformar a realidade onde vive. Assim, convido-lhe a seguir conosco nesse processo de mudança, aprofundar o conhecimento a respeito da atuação do enfermeiro nessa área, colocar o conhecimento especializado a serviço da comunidade, sistematizar ações de prevenção e tratamento de forma a medir e compartilhar resultados, inserir as incontinências em conteúdos programáticos de aulas e palestras, pesquisar melhores abordagens, enfim, fazer a diferença, incorporando a área na assistência, pesquisa, ensino e extensão.

\section{REFERÊNCIAS}

1. Abrams P, Cardozo L, Wagg A, Wein A. Incontinence. 6a ed. Tokyo: International Continence Society; 2017.

2. Brito F, Gentili R. Desatenção à mulher incontinente na atenção primária de saúde no SUS. Fisioter Bras. 2017;18(2):205-13.

3. Paterson J, Ostaszkiewicz J, Suyasa I, Skelly J, Bellefeuille L. Development and validation of the role profile of the nurse continence specialist: a project of the International Continence Society. J Wound Ostomy Continence Nurs. 2016;43(6):641-7. https://doi.org/10.1097/WON.0000000000000286 